\title{
Analysis of potyvirus terminal protein VPg-transgenic Arabidopsis thaliana plants
}

\author{
Izabela Wojtal ${ }^{1}$, Paulina Piontek², Renata Grzela1 ${ }^{1}$, Artur Jarmołowski², Włodzimierz Zagórski , \\ and Jadwiga Chroboczek ${ }^{1,3 凶}$
}

IInstitute of Biochemistry and Biophysics, Polish Academy of Sciences, Warszawa, Poland; ${ }^{2}$ Department of Gene Expression, Faculty of Biology, Adam Mickiewicz University, Poznań, Poland; ${ }^{3}$ Institute of Structural Biology, Grenoble, France

\begin{abstract}
Virus-coded VPg protein of Potato virus $Y$ (PVY) does not have homologs apart from other VPgs. Since VPg is indispensable for the potyvirus life cycle, it appeared a good candidate for eliciting pathogen-derived resistance to PVY. Following agroinfection used to obtain PVY VPg-transgenic Arabidopsis thaliana plants, only few transgenic seeds were recovered giving rise to six transgenic plants that contained the VPg gene with the correct sequence. They generated VPg mRNA, but VPg protein was not detected. Some plants were immune to PVY infection suggesting post-transcriptional gene silencing. However, the likely PVY VPg toxicity exerted at an early stage of transformed seeds development precludes its use for engineering pathogen-derived resistance.
\end{abstract}

Keywords: Potyvirus, VPg protein, transgenic plant, pathogen-derived resistance

Received: 20 January, 2011; revised: 01 July, 2011; accepted: 31 August, 2011; available on-line: 13 September, 2011

\section{INTRODUCTION}

Potyviruses (genus Potyvirus) represent the largest genus of aphid-transmitted plant-infecting viruses that induce harmful diseases in dicot and monocot crop plants. They have a single-stranded messenger-polarity RNA genome of about 10000 nucleotides, a poly(A) tail at the $3^{\prime}$ end, and the a $\mathrm{VPg}$ protein covalently attached to the $5^{\prime}$ terminus. The viral RNA contains a single open reading frame encoding a polyprotein that is cleaved into functional proteins by virus-encoded proteinases (Rajamäki et al., 2004). One of the viral proteins, VPg, is a wellknown virulence factor. Indeed, the covalent tyrosine residue-mediated linkage between $\mathrm{VPg}$ and viral RNA is required for potyvirus infectivity; mutation of the tyrosine residue abolishes viral replication (Murphy et al., 1996). In addition, treatment of virus RNA with proteinase $\mathrm{K}$ that digests $\mathrm{VPg}$ significantly reduces infectivity (Redinbaugh et al., 2001). At the beginning of polyprotein processing VPg exists as a fusion protein NIa, also called VPg-Pro, and is liberated in a free form after autocatalytic cleavage by the Pro protease.

$\mathrm{VPg}$ is responsible for numerous important virushost interactions during the viral infection cycle. It seems to be involved in protein synthesis and cell-tocell and long-distance movement in plant and is a determinant of potyvirus systemic infection in certain host plants (Schaad et al., 1997; Lellis et al., 2002; Rajamaki \& Valkonen, 2002; Dunoyer et al., 2004). Additionally,
$\mathrm{VPg}$ protein interacts with potyviral RNA polymerase $\mathrm{NIb}$ and is involved in genome replication (Schaad et al., 1996; Fellers et al., 1998; Puustinen \& Mäkinen, 2004). Furthermore, it has been found that PVA VPg can be phosphorylated by plant kinases (Ivanov et al., 2001); it was hypothesized that this could trigger the disassembly of infecting virions and the subsequent initiation of potyvirus protein synthesis in the infected cell (Puustinen et al., 2002). The PPV VPg has been shown to interact with two DEAD-box helicase-like proteins from peach and Arabidopsis, which interaction is necessary for the infection with PPV and also with TuMV (Huang et al., 2010). Finally, the PVA VPg interacts with fibrillarin, a nucleolar protein, whose depletion reduces accumulation of infectious virons (Rajamäki \& Valkonen, 2009). Several studies have reported on an interaction between the potyvirus VPg protein and the eukaryotic translation initiation factor eIF4E, which is an mRNA 5 cap-binding protein (Wittmann et al., 1997; Leonard et al., 2000; Duprat et al., 2002; Kang et al., 2005; Grzela et al., 2006; Khan et al., 2008). The key role of this interaction in the virus life cycle is supported by observations that mutations in either $\mathrm{VPg}$ or in eIF4E that abolish this interaction prevent viral infection in planta (Leonard et al., 2000; Duprat et al., 2002; Ruffel et al., 2002; Hwang et al., 2009). All these data underscore the crucial role of VPg in the virus life cycle.

Pathogen-derived resistance (PDR) is a powerful strategy to engineer plant resistance to RNA viruses (Ming et al., 2008, and references therein). It is based on protein-mediated resistance (Powell-Abel et al., 1986; Bendahmane et al., 2007) or, more often, on RNA silencingmediated resistance, known as posttranscriptional gene silencing (PTGS) (Van den Boogaart et al., 2004; Lindbo \& Dougherty, 2005; Voinnet, 2005; Savenkov \& Valkonen, 2002). In plants, PTGS is a gene-regulatory mechanism involved in several control processes, including development, maintenance of genome stability, and defence against invasive pathogens (Matthew, 2004). This process is initiated by double-stranded (dsRNA) or hairpin RNA molecules (Vargas et al., 2008) and results in degradation of cognate cytoplasmic or viral mRNA (Sijen \& Kooter 2000; Aravin et al., 2002; Hammond et al., 2001). Dur-

\email: wisia@ibb.waw.pl; Jadwiga.Chroboczek@imag.fr Abbreviations: A. t., Arabidopsis thaliana (A. thaliana); dpi, days post inoculation; elF4E, eukaryotic initiation factor $4 \mathrm{E}$; Nla, nuclear inclusion protein a; PPV, Plum pox potyvirus; PVA, Potato virus A; PVY, Potato virus Y; TuMV, Turnip mosaic virus; VPg, genome linked viral protein; wt, wild type 
ing silencing, the dsRNA is processed to short interfering RNAs (siRNA) of 21-25 nucleotides by an RNase III-like enzyme called Dicer (Ramachandran \& Chen, 2008). These siRNAs confer specificity on the endonuclease-contning, RNA-induced silencing complex (RISC), which targets homologous RNAs for degradation. It has been well established that PTGS is a major plant defense response against viruses (Ding \& Voinnet, 2007) and viruses have been described as activators as well as targets of this mechanism (Ding et al., 2004; Wang \& Metzlaff, 2005).

Many examples of virus resistance and posttranscriptional gene silencing of endogenous or reporter genes have been described in transgenic plants containing transgenes. The PTGS mechanism is typified by the highly specific degradation of both the transgene mRNA and the target RNA, which contains either the same or complementary nucleotide sequences. The endogenous RNA-dependent RNA polymerase (RdRp) may synthesize dsRNA using the transgene mRNA as a template, resulting in the activation of transgene silencing. If the transgene contains viral sequences, then the viral genomic RNA containing these sequences cannot accumulate in the plant (Waterhouse et al., 1998). Alternatively, transgene mRNA may hybridize to the viral (-)RNA strand (replicative form) to induce silencing, but this situation requires infection and accumulation of a threshold level of the viral RNA. Consequently, transgenic plants expressing virus-derived transgenes may by initially susceptible to homologous viruses and show typical infection symptoms, but new leaves developed later are symptomand virus-free and resistant to subsequent infections with the same virus (Ratcliff et al., 1997; Hamilton et al., 2002; Savenkov \& Valkonen, 2002; Yoo et al., 2004).

We have shown that the VPg protein of PVY is an intrinsically unfolded protein (Grzela et al., 2008), which supports the notion of its multifunctionality and explains one of the mechanisms for its multiple interactions with both viral and host partners. It has been demonstrated that native structural disorder is a weak signal for protein degradation and, in consequence, such proteins have a rather long half-life (Tompa et al., 2008). In addition, PVY VPg does not seem to have any homologs apart from other VPgs, as shown by thorough database screening (P. Siedlecki, personal communication). All these features could be important for pathogen-derived resistance (PDR) based on protein-mediated resistance. Finally and most importantly, this protein is indispensable for successful viral infection; therefore, a mechanism preventing accumulation of VPg mRNA during PVY infection could be useful for engineering plant immunity. For all these reasons we attempted to engineer $A$. thaliana plants expressing VPg of Potato virus $Y$. We then analyzed the effect of the VPg transgene on growth, development and immunity of the transgenic plants.

\section{METHODS AND RESULTS}

Arabidopsis thaliana VPg-transgenic plants were obtained by agroinfection. For this purpose, $V P g$ gene (544 nt) from Potato virus $Y$ (PVY strain 0, accession no. Z29526, British isolate) was amplified by PCR using plasmid pGEX-4T-1_VPg (prepared in our group) as template, digested by $\mathrm{BamHI}$ and $\mathrm{Xba \textrm {I }}$ and inserted into the binary pFP101 vector under the control of the double enhanced cauliflower mosaic virus (CaMV) 35S promoter, yielding plasmid pFP101VPg. This vector contains GFP under the control of the At2S3 seed-specific promoter (Bensmihen et al., 2004). GFP expression allows selection of transgenic Arabidopsis seeds on the basis of their fluorescence, without using any antibiotic or herbicide. Agrobacterium tumefaciens (ASE strain) was transformed with pFP101VPg plasmid in the following way. Competent cells were prepared from $A$. tumifaciens grown at $30^{\circ} \mathrm{C}$ in $\mathrm{LB}$ medium with rifampicin $(50 \mu \mathrm{g} /$ $\mathrm{ml})$ and gentamycin $(20 \mu \mathrm{g} / \mathrm{ml})$, by a standard $\mathrm{CaCl}_{2}$ method. Competent $A$. tumifaciens were transformed with pFPVPg $(1 \mu \mathrm{g})$ and plated on LB agar containing rifampicin, gentamycin and spectinomycin $(70 \mu \mathrm{g} / \mathrm{ml})$. The presence of the $V P g$ gene was demonstrated by cleavage with PstI restriction endonuclease of plasmids purified by a standard method. Recombinant $A$. tumefaciens was used to transform wild-type $A$. thaliana (ecotype Columbia) by the floral dip method (Fraley et al., 1985).

The first experiment generated only one transformed seed. For the second inoculation developmentally younger plants were used, which resulted in nine transformed seeds (F1 progeny). Since in a parallel experiment with the same plant and vector but with a different gene about 100 seeds were obtained, the low number of VPgtransgenic seeds recovered suggested VPg toxicity exerted at an early stage of transformed seed formation.

Transformed F1 seeds were planted and grown for greenhouse experiments under natural daylight supplemented with illumination by sodium halide lamps (photoperiod $16 \mathrm{~h}$, temperature $20 / 25^{\circ} \mathrm{C}$ at night/day). Only six plants were recovered (designated F1_At_VPg1-6 lines), all morphologically similar to wt $A$. thaliana. However, in comparison with wild type plants, the transgenic seedlings grew rather slowly. Seeds (F2 progeny) from each of the F1_At_VPg lines were collected and planted. The F2 progeny, designated F2_At_VPg lines, were screened by RT-PCR and Western blotting for the presence of the VPg transgene and to of the VPg protein. Total RNA was extracted from leaves of 4-weekold seedlings using the Trizol method (http://www. umich.edu/ caparray/PDF/Trizol.pdf), treated carefully with DNase (Promega, Madison, USA) and checked for contamination with genomic DNA by PCR amplification using Taq polymerase (Fermentas). Subsequently, cDNA was synthesized by RT-PCR with an oligo dT(16) primer

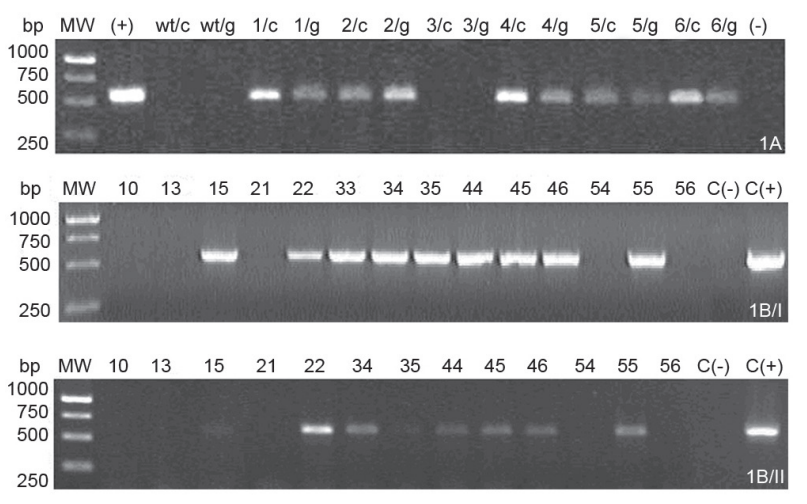

Figure 1. RT-PCR analysis of F2_At_VPg and F3_At_VPg lines with primers specific for the $V P g$ gene

(1A) 1 to 6, F2_At_VPg lines; cDNA (c) and genomic DNA (g) as templates, wt, wild type; $(+)$, positive control (pGEX-4T-1_VPg plasmid); (-), negative control (no template). (1B) 10-56 selected plants from F3_At_VPg lines (see Table 1), cDNA (panel I) or genomic DNA (panel II) as templates, $\mathrm{C}(+)$, positive control (pGEX4T-1_VPg plasmid); C(-), wt A. thaliana DNA, MW, DNA molecular weight markers. 
Table 1. F3 progeny plants selected for molecular analysis Plants with transgene expression are marked in bold.

\begin{tabular}{|c|c|}
\hline F3_At_VPg lines & Selected plants \\
\hline F3_At_VPg1 & $10,13,15$ \\
\hline F3_At_VPg2 & 21,22 \\
\hline F3_At_VPg4 & $33,34,35$ \\
\hline F3_At_VPg5 & $44,45,46$ \\
\hline F3_At_VPg6 & $54, \mathbf{5 5}, 56$ \\
\hline
\end{tabular}

and MMLV reverse transcriptase (Promega, Madison, USA). PVY-specific primers were designed according to the sequence of PVY. RT-PCR of $A$. thatiana actin mRNA was used as an internal control. Western analyses were performed as described by Sambrook et al. (2000) using anti-VPg rabbit polyclonal antibody (prepared in Elevage Scientifique des Dombes in Chatillon, France, using as antigen baculovirus-expressed His-VPg, purified by affinity to $\mathrm{VPg}$ on $\mathrm{CNBr}$-activated Sepharose 4B) (Grzela et al., 2006).

Transgene mRNA was detected in five of six transgenic F2 plants; no transgene mRNA was detected in a plant from the F2_At_VPg3 line (Fig. 1 (1A)). Western blotting performed on protein extract from the transgenic plants with polyclonal antibodies to PVY VPg did not demonstrate any VPg expression (not shown).

Next, the expression and stability of the VPg transgene in F3 progeny was analysed. Seeds from the five F2_At_VPg lines that demonstrated VPg mRNA expression were collected and planted as before. The phenotype of all F3 plants was similar to wt $A$. thaliana plants. Out of the five F3 transgenic lines tested, in only two, F3_At_VPg4 and F3_At_VPg5, was the VPg transgene stable. All randomly selected plants from these two lines transcribed the transgene. In the remaining three lines, only one out of eight plants studied exhibited transgene expression (Fig. 1 (1B) and Table 1). As before, the obtained results were confirmed by PCR reaction with genomic DNA as a template. Finally, detection of VPg was attempted by Western blotting, but the results were again negative (not shown). To exclude the possibility that the lack of VPg expression at the protein level is due to incorrect gene sequence, the sequence of the $V \mathrm{Pg}$ gene incorporated into the genome of transgenic $A$. thaliana was verified; in all F3 progeny plants tested with transgene mRNA expression the sequence of the $V \mathrm{Pg}$ gene was correct. We did not attempt to estimate of the gene copy number as it is clear from numerous communications that there is rarely a correlation between the gene copy number and transgene mRNA abundance on one hand and plant resistance on the other (Zanek et al., 2008; Febres et al., 2008).

In the next step, experiments were initiated to determine whether in the presence of transgene the plants are resistant to infection with the cognate virus. Four F3

Table 2. Analysis of VPg-trangenic F3 plants at 12 days post inoculation with PVY Plants with transgene expression are marked in bold.

\begin{tabular}{llccc}
\hline F3_At_VPg lines & Plant & Inoculated leaves & Non-inoculated leaves & Immunity against PVY \\
\hline F3_At_VPg1 & $\mathbf{1 5}$ & green & green & - \\
F3_At_VPg2 & $\mathbf{2 2}$ & green & green & + \\
& $\mathbf{5 5}$ & yellow-green & green & + \\
F3_At_VPg6 & 56 & green & green & - \\
\hline
\end{tabular}

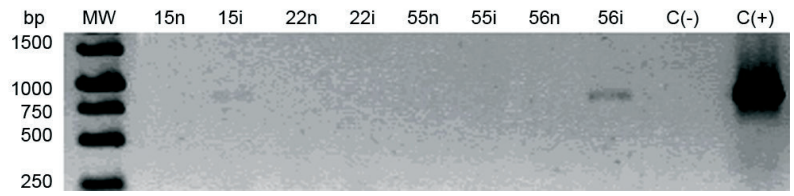

Figure 2. Detection of PVY coat protein (CP) mRNA in infected F3 progeny plants

$n$, non-inoculated leaves; $i$, inoculated leaves; $C(+)$, positive control (Bluescript PVY-CP plasmid); $C(-)$, negative control (no template); 15-56 selected plants (see Table 2); MW, DNA molecular weight markers.

progeny plants, numbers $15,22,55$ and 56 , were selected to study their response to infection with PVY. Three plants (nos. 15, 22 and 55) demonstrated transgene expression while one (no. 56) turned out to be transgeneless and served as a negative control. Five-week-old plants were mechanically inoculated with PVY (strain NTN) on two or three leaves and grown in a growth chamber at $25 / 20^{\circ} \mathrm{C}$ under a long-day photoperiod (16 hours light and 8 hours darkness) at $75 \%$ relative humidity. Seven days post inoculation (dpi) all infected plants were symptom free. At 12 dpi plant no. 55 displayed yellow-green leaves while the others remained green (Table 2). The inoculated and non-inoculated leaves of each selected plants were tested for the presence of PVY coat protein (CP) mRNA, as CP is the most abundant product synthesized during PVY infection; the presence of $\mathrm{CP}$ and the $\mathrm{CP}$ mRNA indicates viral infection (Andrejeva et al., 1999). Hence, expression of CP mRNA was tested by RT-PCR as above. Primers for this analysis were designed to amplify the CP cistron according to the sequence of PVY strain NTN (accession no. AJ889866). Actin mRNA was used as an internal control. CP mRNA was detected in two cases, F3_At_VPg1_15 and F3_At_VPg6_56, in the inoculated leaves only (Fig. 2). Of note, infection of the control plant (no. 56) with PVY did not result in CP expression in non-inoculated leaves.

\section{DISCUSSION}

The scarcity of obtained PVY VPg-transgenic seeds suggested that $\mathrm{VPg}$ introduced serious early defects in transformed plants, which precluded their growth. As a result, only few VPg-transgenic plants could be recovered. The transgenic lines grew almost normally and were morphologically undistinguishable from non-transgenic ones. They contained the correct $V P g$ gene and synthesized presumably correct $\mathrm{VPg} \mathrm{mRNA}$, but no production of VPg protein could be detected by Western blotting. It is relevant that in the case of PVY P1-transgenic potato some plants produced P1 protein but resistance to PVY was not associated with detectable expression of P1 protein (Mäki-Valkama et al., 2000).

Aphids can be controlled by using insecticides. However, since these chemicals are toxic and environmentally deleterious, engineering viral resistance in plants is an attractive approach. The first plants engineered for resistance to viruses were obtained by Powell-Abel et al. (1986). Henceforth, there have been numerous 
attempts to generate virus resistance in transgenic plants based on expression of virus-derived genes or genome fragments, also for PVY (Lawson et al., 1990; Vardi et at., 1993; Pehu et al., 1995; Baulcombe, 1996). In the case of PVY, some interesting results were obtained with potato plants transformed with a fragment of the coat protein (CP) gene, when approximately half of the transformed lines turned out to be resistant to challenge with PVY (Bukovinszki et al., 2007). In addition, NIb gene-transformed potato plants acquired high resistance to PVY under laboratory conditions, but lost it under field conditions (Schubert et al., 2004). Interestingly, transgenic potato plants obtained by transformation with PVY P1 gene were immune to cognate virus but could be infected with a similar virus strain with above $96 \%$ sequence identity, suggesting that factors other than sequence homology might be important for immunity (Mäki-Valkama et al., 2000). Indeed, an interaction of PVY CP protein with host DnaJ-like proteins was observed, and it appeared that tobacco plants deficient in those proteins showed a strong increase in PVY resistance (Hofius et al., 2007); this might explain the anti-viral immunity of CP-transgenic tobacco plants (Bendahmane et al., 2007).

Several attempts have been made to produce transgenic potyviruses-resistant plants using potyvirus VPg-containing sequences. It has been observed that transformation of Nicotiana tabacum plants with sequences corresponding to the fusion protein VPgPro (or NIa) of three potyviruses, Tobacco vein mottling virus (TVMV), Tobacco etch virus (TEV) and PVY, results in plants resistant to infection with the homologous virus (Fellers et al., 1998). However, when Nicotiana benthamiana plants were transformed with $V P g$ gene of Potato virus $A$ (PVA) the transformed lines displayed three different phenotypes: (a) resistance to virus infection, (b) susceptibility, or (c) systemic infection followed by recovery of new leaves (Germundsson \& Valkonen, 2006). Looking for the VPg effect on the suppression of RNA silencing, Germundson et al. (2007) found that two PVA VPg-transgenic lines, tt2 and tt7, readily expressed VPg protein, which did not interfere with the GFP transgene silencing (Germundsson et al., 2007). When tobacco plants were transformed with three genes, each consisting of two different NIa coding regions (TEV NIa-PVY NIa, TEV NIa-TVMV NIa, and TVMV NIaPVY NIa) and with a polyprotein, e.g., NIa-NIb-CP of TEV, of Plum pox virus (PPV) or of TVMV and CI-6K2$\mathrm{NIa}$ or $6 \mathrm{~K} 2-\mathrm{NI} a$ of TEV, the transformed lines displayed similarly three different phenotypes: (a) resistance to virus infection, (b) susceptibility, or (c) systemic infection followed by recovery of new leaves (Schaad et al., 1996; Fellers et al., 1998; Guo et al., 1998; Maiti et al., 1999). Those studies together demonstrated that only a small proportion of the transgenic lines exhibited resistance, and also that the level of resistance was lower following transformation with polyprotein-encoding constructs in comparison with sequences encoding single proteins (Maiti et al., 1999; Germundsson et al., 2007). Moreover, the resistance to viruses was most likely homology-dependent and did not protect the plants against infection with heterologous viruses (Savenkov \& Valkonen, 2001).

The PTGS mechanism is based on sequence similarity between the transgene and the incoming virus. However, in several studies on transgenic plants another hypothetical mechanism is invoked, in which the establishment of plant virus resistance could depend on interactions of the transgene or of transgenic protein with plant machinery (Bendahmane et al., 2007). In a thorough study of trangenic plants made with VPg of another potyvirus, Potato virus $A$, the authors did not report any difficulties in obtaining the VPg-trangenic plants (Germundsson et al., 2007). Transgenic plants abundantly produced $\mathrm{VPg}$ mRNA and some plants did express detectable amounts of the VPg protein. One line (tt6) was resistant to infection, while another line $(\mathrm{tt} 7)$ recovered from infection and was very resistant to superinfection (Germundsson \& Valkonen, 2006). In addition, a PVX-based expression vector containing PVA VPg gene exhibited increased virulence, which could be attributed to a $\mathrm{VPg}$ interaction with the initiation translation factor of the host, eIF4E, affecting host protein synthesis. We have previously shown that PVY VPg protein has quite a high affinity to plant eIF4E (Grzela et al., 2006). We think that the low yield of transgenic seeds as well as the low numbers of transgenic plants obtained stem from the fact that in seeds and plants able to produce PVY $\mathrm{VPg}$, the disturbance of host protein synthesis was so severe that it resulted in early death. In contrast, in transgenic plants in which there was none or very little VPg production (below the threshold of detection by Western blotting) growth was not impaired. In conclusion, despite providing some immunity, the putative PVY VPg toxicity exerted at an early stage of transformed seed formation precludes its use for engineering pathogen-derived resistance.

\section{Acknowledgements}

We are indebted to François Parcy for introduction into techniques and science of transgenic plant formation and to Bogna Szarzynska for help in some experiments. We are grateful to Małgorzata Milner for the gift of the Bluescript PVY-CP plasmid and to Andrzej Paluch for a sample of PVYNTN.

This work was in part supported by the Ministry of Science and Higher Education (Poland), grant No. N302 $04432 / 3571$.

\section{REFERENCES}

Andrejeva J, Puur U, Merits A, Rabenstein F, Jarvekulg L, Valkonen JPT (1999) Potyvirus helper component-proteinase and coat protein (CP) have coordinated functions in virus-host interactions and the same CP motif affects virus transmission and accumulation. J Gen Virol 80: 1133-1139

Aravin AA, Klenov MS, Vagin VV, Rozovskii YM, Gvozdev VA (2002) Role of double-stranded RNA in eukaryotic gene silencing. Mol Biol 36: 180-188.

Baulcombe DC (1996) Mechanisms of pathogen-derived resistance to viruses in transgenic plants. Plant Cell 8: 1833-1844.

Bendahmane M, Chen I, Asurmendi S, Bazzini AA, Szecsi J, Beachy RN (2007) Coat protein-mediated resistance to TMV infection of Nicotiana tabacum involves multiple modes of interference by coat protein. Virology 366: 107-116.

Bensmihen S, To A, Lambert G, Kroj T, Giraudat J, Parcy F (2004) Analysis of an activated ABI5 allele using a new selection method for transgenic Arabidopsis seeds. FEBS Letters 561: 127-131.

Bukovinszki A, Divéki Z, Csányi M, Palkovics L, Balázs E (2007) Engineering resistance to PVY in different potato cultivars in a marker-free transformation system using a 'shooter mutant' $A$. tumefaciens. Plant Cell Rep 26: 459-465.

Ding SW, Voinnet O (2007) Antiviral immunity directed by small RNAs. Cell 130: 413-426.

Ding SW, Li H, Lu R, Li F, Li WX (2004) RNA silencing: a conserved antiviral immunity of plants and animals. Virus Res 102: 109-115.

Dunoyer P, Thomas C, Harrison S, Revers F, Maule A (2004) A cysteine-rich plant protein potentiates potyvirus movement through an interaction with the virus genome-linked protein VPg. J Virol 78: 2301-2309.

Duprat A, Caranta C, Revers F, Menand B, Browning KS, Robaglia C (2002) The Arabidopsis eukaryotic initiation factor (iso) $4 \mathrm{E}$ is dispensable for plant growth but required for susceptibility to potyviruses. Plant J 32: 927-934.

Febres VJ, Lee RF, Moore GA (2008) Transgenic resistance to Citrus tristeza virus in grapefruit. Plant Cell Rep 27: 93-104. 
Fellers JP, Wan J, Hong Y, Collins GB, Hunt AG (1998) In vitro interactions between a potyvirus-encoded, genome-linked protein and RNA-dependent RNA polymerase. J Gen Virol 79: 2043-2049.

Fraley RT, Rogers SG, Horsch RB, Eichholtz DA, Flick JS, Fink CL, Homann NL, Sanders PR (1985) The SEV system: a new disarmed Ti plasmid vector system for plant transformation. BioTechnology 3: 629-635.

Germundsson A, Valkonen JP (2006) P1- and VPg-transgenic plants show similar resistance to Potato virus A and may compromise long distance movement of the virus in plant sections expressing RNA silencing-based resistance. Virus Res 116: 208-213.

Germundsson A, Savenkov EI, Ala-Poikela M, Valkonen JPT (2007) VPg of potato virus A alone does not suppress RNA silencing but affects virulence of a heterologous virus. Virus Genes 34: 387-399.

Grzela R, Strokovska L, Andrieu JP, Dublet B, Zagorski W, Chroboczek J (2006) Potyvirus terminal protein VPg, effector of host eukaryotic initiation factor eIF4E. Biochimie 88: 887-896.

Grzela R, Szolajska E, Ebel C, Madern D, Favier A, Wojtal I, Zagorski W, Chroboczek J (2008) Virulence factor of potato virus Y, genome-attached terminal protein $\mathrm{VPg}$, is a highly disordered protein. $J$ Biol Chem 283: 213-221.

Guo HS, Cervera MT, García JA (1998) Plum pox potyvirus resistance associated to transgene silencing that can be stabilized after different number of plant generations. Gene 206: 263-272.

Hamilton A, Voinnet O, Chappell L, Baulcombe D (2002) Two classes of short interfering RNAs in RNA silencing. EMBO J 21: 46714679 .

Hammond SM, Caudy AA, Hannon GJ (2001) Post-transcriptional gene silencing by double-stranded RNA. Nat Rev Genet 2: 110-119.

Hofius D, Maier AT, Dietrich C, Jungkunz I, Börnke F, Maiss E, Sonnewald U (2007) Capsid protein-mediated recruitment of host DnaJ-like proteins is required for Potato virus $\mathrm{Y}$ infection in tobacco plants. J Virol 81: 11870-11880.

Huang TS, Wei T, Laliberté JF, Wang A (2010) A host RNA helicaselike protein, AtRH8, interacts with the potyviral genome-linked protein, VPg, associates with the virus accumulation complex, and is essential for infection. Plant Physiol 152: 255-266.

Hwang J, Li J, Liu WY, An SJ, Cho H, Her NH, Yeam I, Kim D, Kang BC (2009) Double mutations in eIF4E and eIFiso4E confer recessive resistance to Chilli veinal mottle virus in pepper. Mol Cell 27: 329-336.

Ivanov K, Puustinen P, Merits A, Saarma M, Mäkinen K (2001) Phosphorylation down-regulates the RNA-binding function of the coat protein of potato virus A. J Biol Chem 276: 13530-13540.

Kang BC, Yeam I, Frantz JD, Murphy JF, Jahn MM (2005) The pvr1 locus in pepper encodes a translation initiation factor eIF4E that interacts with Tobacco etch virus VPg. Plant J 42: 392-405.

Khan MA, Miyoshi H, Gallie DR, Goss DJ (2008) Potyvirus genomelinked protein, VPg, directly affects wheat germ in vitro translation: interactions with translation initiation factors eIF4F and eIFiso4F. $J$ Biol Chem 283: 1340-1349.

Lawson C, Kaniewski W, Haley L, Rozman R, Newell C, Sanders P, Tumer NE (1990) Engineering resistance to mixed virus infection in a commercial potato cultivar: Resistance to potato virus $\mathrm{X}$ and potato virus $\mathrm{Y}$ in transgenic Russet Burbank. BioTechnology 8: $127-134$.

Lellis AD, Kasschau KD, Whitham SA, Carrington JC (2002) Loss-ofsusceptibility mutants of Arabidopsis thaliana reveal an essential role for eIF(iso)4E during potyvirus infection. Curr Biol 12: 1046-1051.

Leonard S, Plante D, Wittmann S, Daigneault N, Fortin MG, Laliberté JF (2000) Complex formation between potyvirus VPg and eukaryotic translation initiation factor $4 \mathrm{E}$ correlates with virus infectivity. $J$ Virol 74: 7730-7737.

Lindbo JA, Dougherty WG (2005). Plant pathology and RNAi: a brief history. Ann Rev Phytopathol 43: 191-204.

Maiti IB, Von Lanken C, Hong YL, Dey N, Hunt AG (1999) Expression of multiple virus-derived resistance determinats in transgenic plants does not lead to additive resistance properties. J Plant Biochem Biotechnol 8: 67-73.

Maki-Valkama T, Valkonen JPT, Kreuze JF, Pehu E (2000) Transgenic resistance to PVYO associated with post-transcriptional silencing of the P1 transgene is overcome by PVYN strains that carry highly homologous P1 sequences and recover the transgene expression at infection. Molecular Plant-Microbe Interactions 13: 366-373.

Matthew L (2004) RNAi for plant functional genomics. Comp Funct Genom 5: 240-244.

Ming R, Hou S, Feng Y, Wang L, Alam M (2008) The draft genome of the transgenic tropical fruit tree papaya (Carica papaya Limnaeus). Nature 452: 991-996.

Murphy JF, Klein PG, Hunt AG, Shaw JG (1996) Replacement of the tyrosine residue that links a potyviral VPg to the viral RNA is lethal. Virology 220: 535-538.

Pehu TM, Mäki-Valkama TK, Valkonen JPT, Koivu KT, Lehto KM, Pehu EP (1995) Potato plants transformed with a potato virus Y P1 gene sequence are resistant to PVY0. Am Potato J 72: 523-532.
Powell-Abel P, Nelson RS, De B, Hoffmann N, Rogers SG, Fraley RT, Beachy RN (1986) Delay of disease development in transgenic plants that express the tobacco mosaic virus coat protein gene. Science 232: 738-743.

Puustinen P, Mäkinen K (2004) Uridylylation of the potyvirus VPg by viral replicase NIb correlates with the nucleotide binding capacity of VPg. J Biol Chem 279: 38103-38110.

Puustinen P, Rajamäki ML, Ivanov KI, Valkonen JP, Mäkinen K (2002) Detection of the potyviral genome-linked protein VPg in virions and its phosphorylation by host kinases. J Virol 76: $12703-$ 12711.

Rajamäki ML, Valkonen JP (2002) Viral genome-linked protein (VPg) controls accumulation and phloem-loading of a potyvirus in inoculated potato leaves. Mol Plant Microbe Interact 15: 138-149.

Rajamäki ML, Mäki-Valkama T, Mäkinen, K, Valkonen JPT (2004) Infection with potyviruses. Plant-Pathogen Interactions, pp 68-91. Blackwell Publishing, Oxford, UK.

Rajamäki ML, Valkonen JP (2009) Control of nuclear and nucleolar localization of nuclear inclusion protein a of picorna-like Potato virus A in Nicotiana species. Plant Cell 21: 2485-2502.

Ramachandran V, Chen X (2008) Small RNA metabolism in Arabidopsis. Trends Plant Sci 13: 368-374.

Ratcliff F, Harrison BD, Baulcombe DC (1997) A similarity between viral defence and gene silencing in plants. Science 276: 1558-1560.

Redinbaugh MG, Louie R, Ngwira P, Edema R, Gordon DT, Bisaro DM (2001) Transmission of viral RNA and DNA to maize kernels by vascular puncture inoculation. J Virol Methods 98: 135-143.

Ruffel S, Dussault MH, Palloix A, Moury B, Bendahmane A, Robaglia C, Caranta C (2002) A natural recessive resistance gene against potato virus $\mathrm{Y}$ in pepper corresponds to the eukaryotic initiation factor 4E (eIF4E). Plant J 32: 1067-1075.

Sambrook J, Fritsch EF, Maniatis T (2000) Molecular Cloning: a laboratory manual. 3rd edn. Cold Spring Harbor Laboratory, Cold Spring Harbor Laboratory Press, NY.

Savenkov EI, Valkonen JP (2001) Coat protein gene-mediated resistance to potato virus A in transgenic plants is suppressed following infection with another potyvirus. J Gen Virol 82: 2275-2278.

Savenkov EI, Valkonen JPT (2002) Silencing of a viral RNA silencing suppressor in transgenic plants. I Gen Virol 83: 2325-2335.

Schaad MC, Haldeman-Cahill R, Cronin S, Carrington JC (1996) Analysis of the VPg-proteinase (NIa) encoded by tobacco etch potyvirus: effects of mutations on subcellular transport, proteolytic processing, and genome amplification. J Virol 70: 7039-7048.

Schaad MC, AD Lellis, Carrington JC (1997) VPg of tobacco etch potyvirus is a host genotype-specific determinant for long-distance movement. J Virol 71: 8624-8631.

Schubert J, Matousek J, Mattern D (2004) Pathogen-derived resistance in potato to Potato virus Y-aspects of stability and biosafety under field conditions. Virus Res 100: 41-50.

Sijen T, Kooter M (2000) Post-transcriptional gene silencing: RNAs on the attack or on the defense? Bio-Essays 22: 520-531.

Tompa P, Prilusky J, Silman I, Sussman JL (2008) Structural disorder serves as a weak signal for intracellular protein degradation. Proteins 71: $903-909$.

Van den Boogaart T, Maule AJ, Davies JW, Lomonossoff GP (2004) Sources of target specificity associated with the recovery against Pea seed borne mosaic virus infection mediated by RNA silencing in pea. Molecular Plant Pathology 5: 37-44

Vardi E, Sela I, Edelbaum O, Livneh O, Kuznetsova L, Stram Y (1993) Plants transformed with a cistron of a potato virus Y protease (NIa) are resistant to virus infection. Proc Natl Acad Sci USA 90: 7513-7517.

Vargas M, Martínez-García B, Díaz-Ruíz JR, Tenllado F (2008) Transient expression of homologous hairpin RNA interferes with PVY transmission by aphids. Virol J 19: 5-42.

Voinnet $\mathrm{O}$ (2005) Induction and suppression of RNA silencing: insights from viral infections. Nature Rev Genet 6: 206-220.

Wang MB, Metzlaff M (2005) RNA silencing and antiviral defense in plants. Curr Opin Plant Biol 8: 216-222.

Waterhouse PM, Graham MW, Wang MB (1998) Virus resistance and gene silencing in plants can be induced by simultaneous expression of sense and antisense RNA. Proc Natl Acad Sci USA 95: 1395913964.

Wittmann S, Chatel H, Fortin MG, Laliberté JF (1997) Interaction of the viral protein genome linked of Turnip mosaic potyvirus with the translational eukaryotic initiation factor (iso) $4 \mathrm{E}$ of Arabidopsis thaliana using the yeast two-hybrid system. Virology 234: 84-92.

Yoo BC, Kragler F, Varkonyi-Gasic E, Haywood V, Archer-Evans S, Lee YM, Lough TJ, Lucas WJ (2004) A systemic small RNA signaling system in plants. Plant Cell 16: 1979-2000.

Zanek MC, Reyes CA, Cervera M, Peña EJ, Velázquez K, Costa N, Plata MI, Grau O, Peña L, García ML (2008) Genetic transformation of sweet orange with the coat protein gene of Citrus psorosis virus and evaluation of resistance against the virus. Plant Cell Rep 27: $57-66$. 